\title{
Automatic detection of surface-water bodies from Sentinel-1 images for effective mosquito larvae control
}

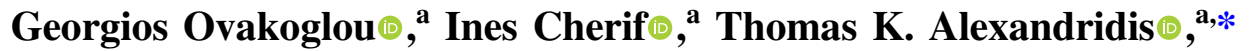 \\ Xanthoula-Eirini Pantazi, ${ }^{b}$ Afroditi-Alexandra Tamouridou $\odot$, \\ Dimitrios Moshou, ${ }^{\text {b }}$ Xanthi Tseni, ${ }^{\mathrm{c}}$ Iason Raptis $\odot,{ }^{\mathrm{c}}$ \\ Stella Kalaitzopoulou, ${ }^{c}$ and Spiros Mourelatos ${ }^{\mathrm{c}}$ \\ a Aristotle University of Thessaloniki, School of Agriculture, Laboratory of Remote Sensing, \\ Spectroscopy and GIS, Thessaloniki, Greece \\ ${ }^{\mathrm{b}}$ Aristotle University of Thessaloniki, School of Agriculture, Laboratory of Agricultural \\ Engineering, Thessaloniki, Greece \\ ${ }^{c}$ Ecodevelopment S.A., Thessaloniki, Greece
}

\begin{abstract}
Surface-water body maps are imperative for effective mosquito larvae control. This study aims to select a method for the automatic and regular mapping of surface-water bodies in rice fields and wetlands using Sentinel-1 synthetic aperture radar data. Four methods were adapted and developed for automated application: the Otsu valley-emphasis algorithm, a classification method based on the textural feature of entropy, a method using $K$-means unsupervised classification, and a method using the Haralick's textural feature of dissimilarity and fuzzy-rules classification. The results were assessed using field data collected during the mosquito breeding periods of 2018 and 2019 in the region of Central Macedonia (Greece). The Otsu valley-emphasis technique provides the highest overall accuracy (0.835). The accuracy is higher at the beginning of the summer (0.948) than at the end of the rice-growing season due to higher density of vegetation. Results using this method were further assessed during the main larvicide application period. The presence of vegetation, built-up areas, floating algae in rice-paddies, salt-crust formations in wetlands, and water depth, were found to affect the performance of the algorithm. A WebGIS platform was designed for the visualization of the produced water maps along with other data related to mosquito-larvae presence. (C) The Authors. Published by SPIE under a Creative Commons Attribution 4.0 Unported License. Distribution or reproduction of this work in whole or in part requires full attribution of the original publication, including its DOI. [DOI: 10.1117/1.JRS.15.014507]
\end{abstract}

Keywords: water bodies mapping; monitoring; wetlands; rice fields; WebGIS.

Paper 200665 received Sep. 6, 2020; accepted for publication Jan. 25, 2021; published online Feb. 18, 2021.

\section{Introduction}

Surface-water bodies are important breeding habitats of mosquitoes, thus, surface-water body maps together with other parameters (meteorological and phenological) are often used as predictors of mosquito larvae presence. ${ }^{1}$ Regular monitoring of surface-water bodies in near realtime (NRT) is necessary for the timely prevention of outbreaks, such as the Rift Valley Fever ${ }^{2}$ or the West Nile Virus (WNV). The latter accounts for high numbers of human cases and fatalities, and for large outbreaks in Greece (during the periods 2010-2014 and 2017-2019, a total of more than 1.200 human cases were identified) and other European countries. A way of limiting the number of infections is through the effective mosquito population control, where exhaustive larviciding is the most commonly used practice worldwide. The mapping of surface-water areas can be achieved through observation and recording in the field. However, such a process is timeconsuming and costly in human resources and budget, ${ }^{3,4}$ especially when a wide area needs to be covered. The use of unmanned aircraft systems (UAS) for the acquisition of aerial photographs in the areas of interest is considered a widespread practice, but the resources and equipment

*Address all correspondence to Thomas K. Alexandridis, thalex@agro.auth.gr 
required (UAS, suitable sensors, human resources for the operation of the UAS, and the analysis of aerial photographs) are prohibitive for large-scale water maps. ${ }^{5}$ While several studies have used satellite data (optical and/or radar) to identify surface-water areas at different spatial and temporal scales, the requirements for an operational surface-water monitoring system for mosquito larvae prediction (accuracy, ease of integration, automation, frequency of update, and robustness under cloudy conditions) are not all met.

Optical data have been used to identify surface-water areas, exploiting the fact that clear water absorbs almost all near-infrared irradiance, in contrast to the highly reflecting nearby soil or vegetation. Based on this principle, Ovakoglou et al. ${ }^{6}$ used time-series of Moderate Resolution Imaging Spectroradiometer and Landsat images to develop a methodology for monitoring inundated areas in Lake Kerkini (Greece), a water body characterized by a wide fluctuation of the water level throughout the year. In their study, the data relevant to water-level gauges were acquired in the field for the dates of interest, whereas it is possible to also automatize this process through the method proposed by Chemin, Rabbani. ${ }^{7}$ Lacaux et al. ${ }^{8}$ used the normalized difference pond index (NDPI) and the normalized difference turbidity index (NDTI) from Satellite Pour l' Observation de la Terre (SPOT)-5 with a spatial resolution of $10 \mathrm{~m}$ to detect changes in lakes (or temporarily formed lakes) with a minimum surface area of $100 \mathrm{~m}^{2}$. Dambach et al. ${ }^{9}$ used the NDPI, NDTI, and normalized difference vegetation index (NDVI) indices derived from SPOT-5 data, in combination with data related to soil morphology and hydrology, to analyze the possible spread of WNV from mosquito populations of the species Culex poicipibe. Vignolles et al. ${ }^{10}$ used the NDVI, NDPI, normalized difference water index (NDWI), and modified normalized difference water index (MNDWI) in combination with land use and land cover maps to identify and analyze possible mosquito habitats in selected areas. From the various indices used, the NDWI index ${ }^{11}$ was considered to be directly related to the density of mosquito populations and in particular to larvae populations. ${ }^{12}$ However, the use of optical satellite data for the regular and operational mapping of surface-water bodies has limitations due to cloud contamination of the images and darkness during night hours.

Remote sensing methods based on the use of radar (microwave) sensors seem to be more suitable for monitoring water areas, offering the advantage of uninterrupted data supply (dayand-night) under any weather conditions, and the ability - under certain circumstances- to detect inundated areas covered by vegetation. The principle of using side-looking radar images in mapping water bodies is based on the smooth water surface that acts as a specular reflector, whereas the surrounding environment (soil and vegetation) are diffuse reflectors. The result is low backscatter at water surfaces, which contrasts to higher backscatter of soil and vegetation morphology. ${ }^{13}$ Limitations in using radar data include the minimum size of detectable objects and the sensors' positioning in the satellite's field of view. ${ }^{4}$ The latter leads to the presence of shadows or blind areas in the synthetic aperture radar (SAR) satellite images, which are falsely interpreted as water surfaces. ${ }^{14}$ Nelson et al. ${ }^{15}$ point out that maximum accuracy in the acquisition of backscatter values by a SAR sensor over water bodies can be achieved when the incidence angle is high, avoiding this way the effect of the wind (presence of waves), and increasing the dynamics of the backscatter signal. According to Betbeder et al., ${ }^{16}$ the band $\mathrm{L}$ of Japan Earth Resources Satellite-1 and Advanced Land Observation satellites is suitable for mapping and monitoring dense forest wetlands. SAR waves have the potential to penetrate the forest vegetation, and the signal interaction with the underlying flooded vegetation produces a double-bounce mechanism that allows the detection of flooded forest areas. SAR data were used for mapping water surrounded by different vegetation cover as it was applied for flooded areas mapping, ${ }^{2}$ rice field mapping, ${ }^{17}$ and wetland monitoring. ${ }^{16}$

Until recently, SAR sensors were characterized by low temporal resolution (revisiting period 24-35 days), ${ }^{13}$ which negatively affected the systematic and frequent monitoring of changes in water surfaces. Sentinel-1 data significantly improved the frequency at which SAR data could be available, which is every six days in Greece when utilizing both Sentinel-1a and 1b satellites. Very high-spatial resolution SAR sensors (such as TerraSAR-X and RADARSAT-2) offer the possibility of mapping and monitoring the duration of inundation phenomena at the field scale. Flooded grassland for example has a higher number of polarimetric mechanisms, and higher regression factors compared to non-flooded areas. Vignolles et al. ${ }^{18}$ used TerraSAR-X data with a spatial resolution of $3 \mathrm{~m}$ to create a Rift Valley fever virus spread-prevention model. Bourgeau-Chavez 
et al. ${ }^{19}$ suggested the use of multi-frequency and multi-polarity SAR data for integrated wetland monitoring. Henry et al. ${ }^{20}$ concluded that the use of horizontal-vertical polarity radar data offers improved accuracy in detecting flooded areas, compared to single horizontal-horizontal ( $\mathrm{HH})$ polarity data. Twele et al. ${ }^{21}$ investigated whether a TerraSAR-X (X-band) based automated flood monitoring model developed by Martinis et al. ${ }^{22}$ could be adapted to the use of Sentinel-1 (Cband) data. They conclude that the HH polarity mode available through TerraSAR-X combined with the improved spatial resolution of the TerraSAR-X products (3-m spatial resolution instead of 10-m spatial resolution in Sentinel-1 data) lead to greater accuracy in the detection of surfacewater bodies, and in reducing false alarms. However, wider coverage images should be used for monitoring of large areas (e.g., at Regional level) such as Sentinel-1 data that are provided free-ofcost by the European Space Agency (ESA) through the Copernicus scientific hub platform. ${ }^{23}$ An additional advantage is the capability of acquiring data automatically through an application program interface (API), making it possible to create automated surface-water detection models operating at NRT. Various studies have demonstrated the use of Sentinel-1 SAR data for the detection of inundated areas, ${ }^{21,24-27}$ with the majority of them suggesting that data of verticalvertical polarity capture more accurately the water surfaces compared to datasets with other polarity modes. Additionally, they suggest the use of the Ground Range Detected (GRD) product of Sentinel-1, which comes at a spatial resolution of $10 \mathrm{~m}$. Phase information are not available for the GRD products and therefore, the total size of the files is significantly reduced compared to the single-look-complex products of Sentinel-1 (1 GB instead of $4 \mathrm{~GB}$ ), making GRD products more convenient for operational use (due to the reduced processing power needed) and keeping low the data storage needs.

The aim of this work is to develop an automated methodology for detecting surface-water bodies in wetlands and agricultural land using Sentinel-1 data. Of those adapted and tested, the accuracy was evaluated from a large in-situ dataset. Finally, the impact of environmental factors was further analyzed. The resulting surface-water maps will be provided to users through a WebGIS facility and will be used in a decision support system for targeted and effective larvicide application in mosquito breeding habitats.

\section{Materials and Methods}

\subsection{Study Area}

The study area is located in the region of Central Macedonia in Greece (see Fig. 1). The total area extent is $275 \mathrm{~km}^{2}$ including wetlands $\left(51.5 \mathrm{~km}^{2}\right)$ and rice fields $\left(223.5 \mathrm{~km}^{2}\right)$, which are the main habitats of mosquito breeding in the region. In particular, the study area includes the following four wetlands ecosystems: Axios river delta, Galikos river estuaries, Kalochori lagoon, Mikra swamps, and lagoons of Epanomi and Aggelohori. These wetlands represent the most productive ecosystems in mosquito larvae in the region of Central Macedonia. The agricultural area of the plain of Thessaloniki is flat and is served by an open channel irrigation and drainage network. The main crop is rice, and to a lower extent maize, alfalfa and cotton.

\subsection{Sentinel-1 Data Acquisition and Pre-Processing}

The Sentinel-1 images used for the testing and comparison of the water detection algorithms were acquired already pre-processed through the Google Earth Engine (GEE) platform. Images of two dates during the summer period (June 12, 2019 and August 29, 2019) were used for the comparison between all water-presence detection methods tested and images of four additional dates (see Table 1 for the exact dates) were used to further test the method found to provide the most accurate results (see Sec. 3), and to compare the accuracy achieved between the two thresholding methods developed (Otsu and Otsu Valley-emphasis, see section Sec. 2.4.1). All Sentinel-1 images were GRD products acquired in descending orbit direction with the Interferometric Wide swath instrument mode. The files are georeferenced using the earthly ellipsoid model of the World Geodetic System 1984 (WGS84). The GRD products are geometrically corrected using ground elevation information, specified by the product's metadata. 


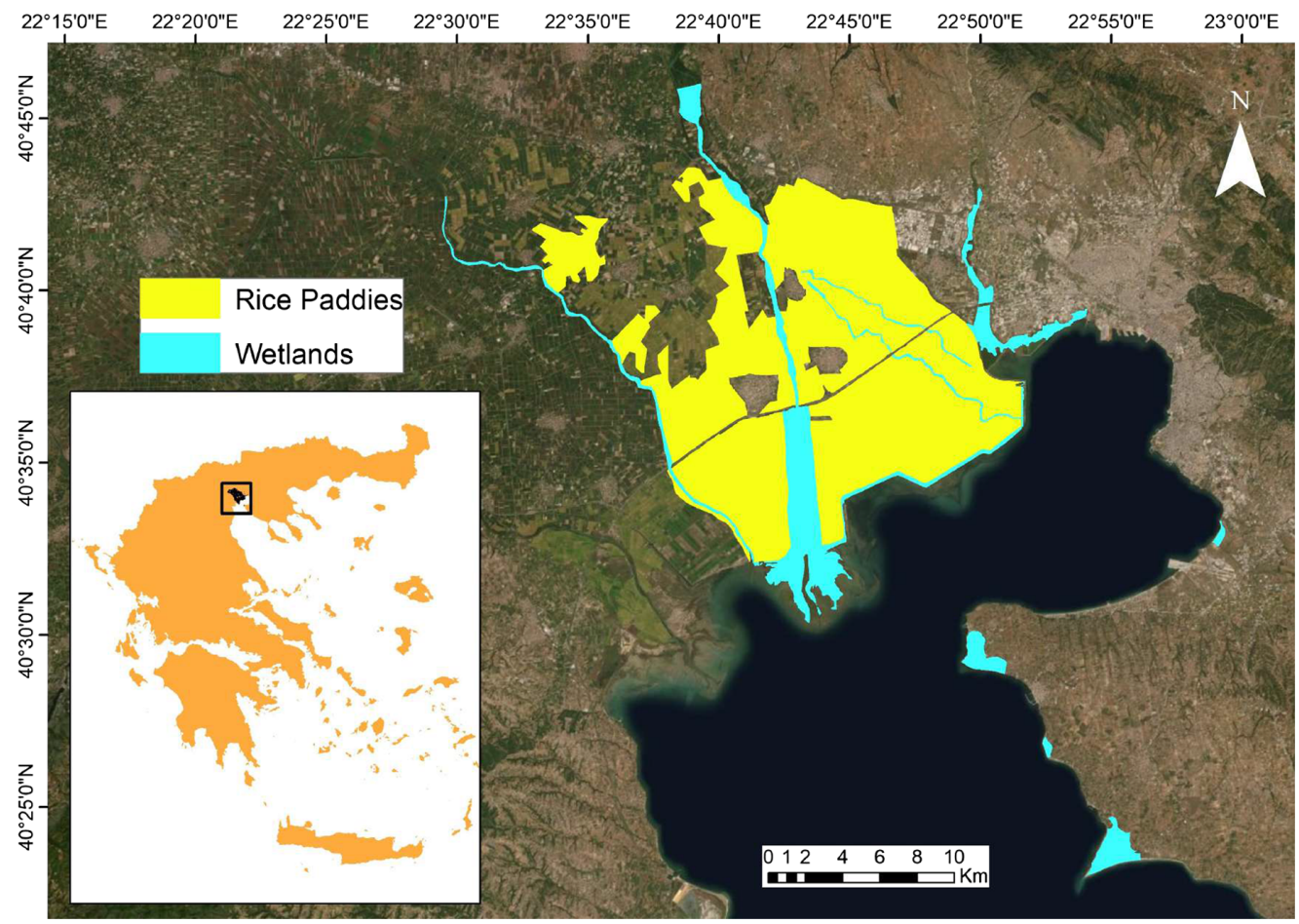

Fig. 1 Location of rice paddies and wetlands in the study area.

Table 1 Number of polygons collected, sorted by water condition and land use.

\begin{tabular}{|c|c|c|c|c|c|c|c|c|}
\hline \multirow[b]{2}{*}{$\begin{array}{l}\text { SAR image } \\
\text { acquisition dates }\end{array}$} & & \multicolumn{4}{|c|}{ Polygon inundation state } & \multicolumn{3}{|c|}{ Polygon land use } \\
\hline & & $\begin{array}{l}100 \% \\
\text { dry }\end{array}$ & Mixed & $\begin{array}{c}100 \% \\
\text { inundated }\end{array}$ & Total & $\begin{array}{l}\text { Rice } \\
\text { fields }\end{array}$ & Wetlands & Other \\
\hline \multirow{2}{*}{$\begin{array}{l}\text { Comparison between } \\
\text { all methods }\end{array}$} & June 12, 2019 & 25 & 24 & 5 & 54 & 20 & 8 & 26 \\
\hline & August 29, 2019 & 9 & 15 & 10 & 34 & 20 & 6 & 8 \\
\hline \multirow{4}{*}{$\begin{array}{l}\text { Further testing of the } \\
\text { most accurate method }\end{array}$} & June 23, 2018 & 12 & 30 & 10 & 52 & 25 & 27 & 0 \\
\hline & May 07, 2019 & 21 & 10 & 17 & 48 & 20 & 21 & 7 \\
\hline & May 25, 2019 & 2 & 6 & 16 & 24 & 20 & 0 & 4 \\
\hline & May 31, 2019 & 23 & 22 & 12 & 57 & 20 & 18 & 19 \\
\hline
\end{tabular}

The pre-processing routines applied to the Sentinel-1 images by GEE include the application of an orbit file, the border-noise removal, the removal of thermal noise, and the radiometric and geometric correction of the Sentinel-1 images. More technical details about the GEE pre-processing routines can be found in Ref. 28. Additionally, the Sentinel-1 toolbox of SeNtinels' Application Platform (SNAP) software was used for the application of Lee's speckle-filter ${ }^{29}$ on the pre-processed images, for the reduction of salt-and-pepper effects present in the associated SAR images. ${ }^{30}$ A $3 \times 3$ processing window, as suggested by Amitrano et al. ${ }^{26}$ was used after testing different window sizes to minimize the speckle noise.

Meteorological data for the days and areas of interest were also used to check the presence of strong winds, which is reported to affect the accuracy of SAR-based water detection algorithms, due to the formulation of waves at the water surface. ${ }^{24}$ Moreover, the Digital Elevation Model of Shuttle Radar Topography Mission at a spatial resolution of $30 \mathrm{~m}$ was used to exclude areas with altitude over $300 \mathrm{~m}$ (out of present study's scope according to the larviciding application 
protocol), and to produce the height above next drainage (HAND) index ${ }^{31}$ within the study area. The HAND index was used to avoid water presence false alarms ${ }^{32}$ by excluding areas with low probability of being inundated for consecutive days. The HAND index threshold value of exclusion for the study area was set to be over $15 \mathrm{~m}(>15 \mathrm{~m})$, which was found after testing and according to local topography experts to be the value including all areas of interest.

\subsection{Field Data}

Field data were collected on dates concurrent with the Sentinel-1 images' acquisition and consist of various wetland and rice polygons within the study area, where the status of water and vegetation was recorded. The minimum required size of the sampling polygons was set to approximately $1000 \mathrm{~m}^{2}$ considering the pixel size of the Sentinel-1 data $(10 \mathrm{~m})$, to retain sufficient pixels per polygon for the validation process. As a result, the acreage of in-situ sampled polygons ranged between $963 \mathrm{~m}^{2}$ and 70.7 ha. Additional polygons of other land uses (e.g., with other types of crops, buildings, or greenhouses) were also surveyed as they are reported in relevant literature as common false alarms for water detection algorithms. ${ }^{33}$ The location of the polygons was recorded using a GPS and digital photos were taken in-situ. The polygons were characterized as homogeneous (either completely dry or completely inundated) and heterogeneous (with mixed presence of dry and inundated areas, see Table 1). An internal buffer of $5 \mathrm{~m}$ from the perimeter of each polygon was applied to exclude mixed land uses at the border of the polygons (e.g., roads and canals) of the validation dataset. The additional information collected in the field for each polygon is the percentage of vegetation cover and its height in each polygon, the percentage of the polygon covered by water and its depth. These characteristics were intended to be used to examine the capability of the SAR images to detect inundated areas under vegetation and to assess the effect of water depth on water detection using SAR data.

\subsection{Water Mapping Methods}

\subsubsection{Automated Thresholding Methods}

Various studies apply a threshold value on SAR backscatter data to identify inundated areas. The threshold value can be set manually by a human operator after examining the distribution of backscatter values on the SAR image's histogram or can be set automatically as demonstrated by various studies. ${ }^{34-36}$ Two methods were tested for the automatic detection of a threshold value for water presence: (a) the Otsu method ${ }^{37}$ and (b) the Otsu Valley-emphasis method. ${ }^{34}$ Both methods were implemented using Matlab software, providing as output binary images of water presence in Geotiff format.

Otsu method. The image binarization method developed by Otsu automatically calculates a threshold value $(t)$ from an image's pixels value histogram, minimizing the weighted withinclass variance given by the relation:

$$
\sigma_{w}^{2}(t)=q_{1}(t) \sigma_{1}^{2}(t)+q_{2}(t) \sigma_{2}^{2}(t),
$$

where $q_{1}$ and $q_{2}$ are the sum $(\Sigma)$ of probabilities $(P)$ for the two classes separated by a threshold $(t)$, and $\sigma_{1}^{2}$ and $\sigma_{2}^{2}$ are variances of these two classes, computed from the histogram of the $\mathrm{L}$ distinct gray-levels of the image, as follows:

$$
\begin{aligned}
& q_{1}(t)=\sum_{i=1}^{t} P(i), \\
& q_{2}(t)=\sum_{i=t+1}^{L} P(i),
\end{aligned}
$$




$$
\begin{aligned}
\sigma_{1}^{2}(t) & =\sum_{i=1}^{t}\left[i-\mu_{1}(t)\right]^{2} \frac{P(i)}{q_{1}(t)}, \\
\sigma_{2}^{2}(t) & =\sum_{i=t+1}^{t}\left[i-\mu_{2}(t)\right]^{2} \frac{P(i)}{q_{2}(t)},
\end{aligned}
$$

where class means $(\mu 1$ and $\mu 2)$ are computed as follows:

$$
\begin{aligned}
& \mu_{1}(t)=\sum_{i=1}^{t} \frac{i P(i)}{q_{1}(t)}, \\
& \mu_{2}(t)=\sum_{i=t+1}^{I} \frac{i P(i)}{q_{2}(t)} .
\end{aligned}
$$

The Otsu method works accurately for images with histograms of bimodal pixel value distribution (i.e., two peaks are present in the histogram), whereas it is less accurate when applied on histograms of unimodal distribution (i.e., one peak is present in the histogram).

Otsu Valley-Emphasis Method. The modification of Otsu algorithm proposed by $\mathrm{Ng}^{34}$ uses the same basic technique as the original Otsu method but gives more weight to the points between the two peaks of bimodal distribution histograms (valley) or to the bottom of the histogram (low-value histogram area) in cases of unimodal histograms. The optimal threshold value $(t *)$ using the valley-emphasis method is computed as follows:

$$
t^{*}=\underset{0 \leq t<L}{\operatorname{ArgMax}}\left\{\left(1-P_{t}\right)\left(q_{1}(t) \mu_{1}^{2}(t)+q_{2}(t) \mu_{2}^{2}(t)\right)\right\},
$$

where all the variables remain the same as described in the original Otsu's method given above, and ArgMax refers to the inputs -or arguments- at which the function outputs are as large as possible. Therefore, the Otsu valley-emphasis method is considered to provide improved accuracy compared to the Otsu method in cases of unimodal distribution histograms, whereas the application of the two methods in bimodal distribution images returns comparable threshold values since both methods attempt to maximize the between-group variance of the histogram.

\subsubsection{Method Based on the Textural Feature of Entropy}

The classification of pre-processed Sentinel-1 images into $K$-clusters and the use of the textural characteristic of entropy have been proposed by $\mathrm{Li}$ and $\mathrm{Wang}^{38}$ for the identification of surfacewater bodies. Entropy (ENT) defines the complex degree of an image's texture and is calculated using the gray-level co-occurrence matrix $(\mathrm{GLCM})^{39}$ by the equation:

$$
\mathrm{ENT}=-\sum_{i} \sum_{j} p(i, j) \log p(i, j)
$$

where $p(i, j)$ is the $(i, j)$ 'th entry of the normalized GLCM. The method was adapted for the needs of the present study and an algorithm was developed (see Fig. 2 for the detailed flowchart) using as input Sentinel-1 pre-processed images to:

Perform $K$-means cluster analysis and create an initial mask (image) of areas with water presence and a mask with the areas characterized by low backscatter values. A total of 20 clusters was used as suggested by the authors of the original method, which was also verified as the optimal configuration after testing with local data.

Create an image of the entropy textural characteristic.

Apply the Otsu algorithm on the histograms of the entropy image and of the initial water mask image created in step (a) to automatically detect the threshold value indicating the inundated areas. 


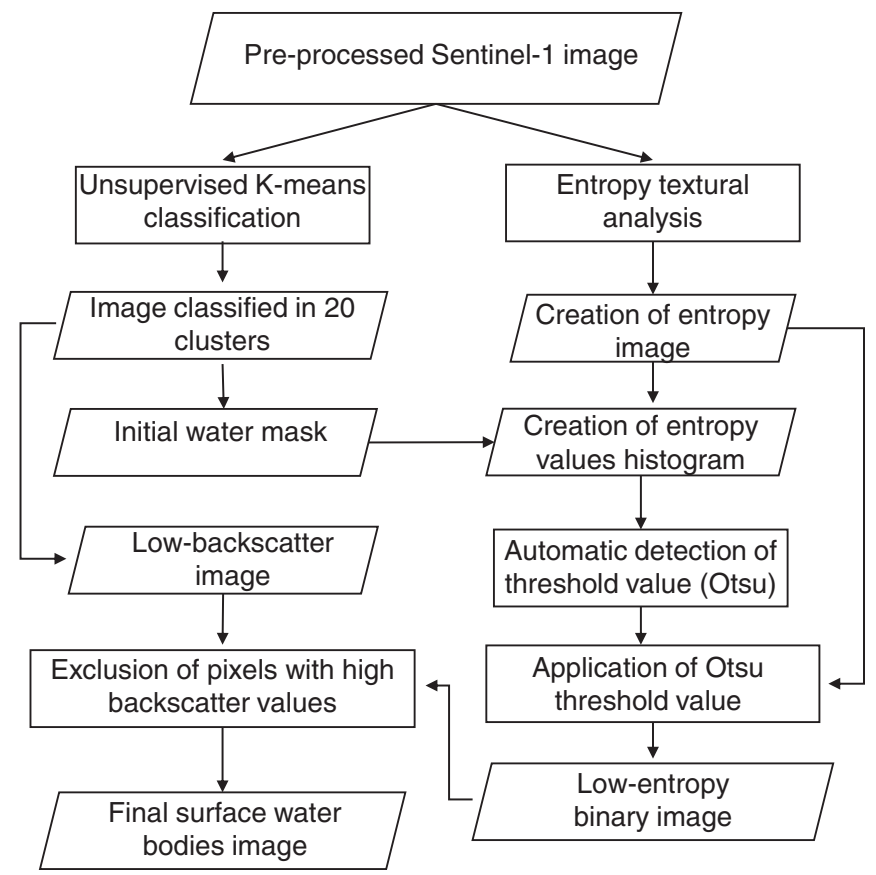

Fig. 2 Flowchart of water detection method based on the textural feature of entropy.

The SNAP software was used to apply the $K$-means clustering analysis and for the creation of the entropy image. The Otsu thresholding method was applied using Matlab software, providing the final output water maps in Geotiff format.

\subsubsection{Method Based on K-Means Unsupervised Classification}

Since the method proposed by $\mathrm{Li}$ and Wang ${ }^{38}$ in the previous section creates an initial map of surface-water using an unsupervised $K$-means classification, this initial map was assessed in comparison with the results of the other methods. This method was found not to be fully automatic though, as the number of output classes varies from one image to the other.

\subsubsection{Method Based on the Textural Feature of Dissimilarity and Fuzzy-Rules Classification Techniques}

Amitrano et al. ${ }^{26}$ developed a method (Fig. 3) for the direct mapping of flooded areas using Sentinel-1 data. The method is based on using the classic Haralick's textural features ${ }^{40}$ and in particular the textural feature of dissimilarity. The method was developed as follows.

1. The histogram values of the image were clipped (histogram clipping at 95\%) to compensate for the presence of objects in the image with high reflection values, ${ }^{41,42}$ enhancing this way the visual display sharpness of areas with low-reflection values.

2. The Haralick's textural feature of dissimilarity $(D)$ was then calculated using a $5 \times 5$ pixels window to optimize the time needed for processing the image and the resistance to outlier values.

3. $D$ from step (2) was used to estimate the complementary characteristic of similarity $(S)$, using the following equation:

$$
S=1-D
$$

4. The values in the images created through steps (1) and (3) were normalized with respect to their maximum values so that the new values range between 0 and 1 . 


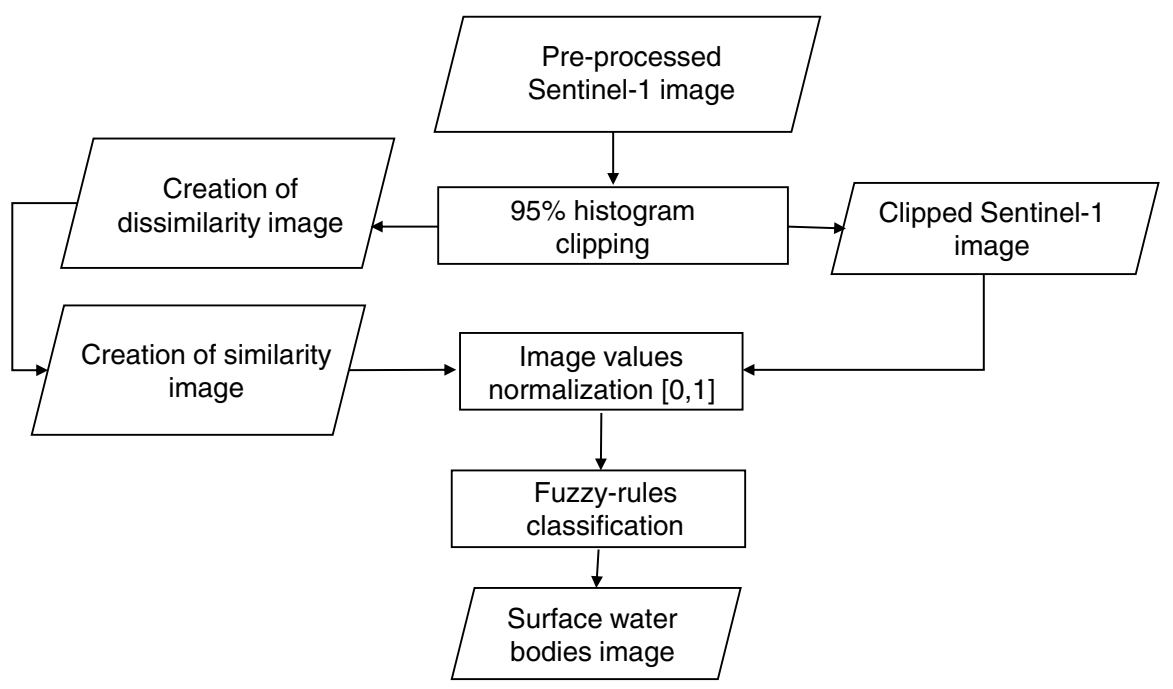

Fig. 3 Flowchart of the method based on the textural feature of dissimilarity and fuzzy-rules classification techniques.

5. The normalized images of step (4) were used as input data to apply the classification method with fuzzy rules.

The two variables similarity and intensity were categorized into two fuzzy-classes "low" and "high" using Z-type and $S$-type fuzzy functions. Areas with water are those with high values of similarity and low backscatter values. Adopting a set of fuzzy classification rules avoids searching for a specific threshold value. In fact, the categories "water area" and dry land were automatically attributed through defuzzification of the probability maps created by the fuzzy system. This step was implemented using the maximum membership method. ${ }^{43}$ The SNAP software was used to calculate the textural features of dissimilarity and similarity while the fuzzy system was developed using the Matlab software.

\subsection{Evaluation Methods}

Confusion matrices were created for the assessment of the results in the homogeneous polygons obtained with the four tested surface-water detection methods. A confusion matrix is a twodimensional table where the columns correspond to the observations in the field (actual status) and the rows to the predicted values (estimations). The cells in the matrix refer to the following terms:

1. True positive (TP) predictions: water presence is correctly predicted at pixels in inundated polygons.

2. True negative (TN) predictions: water absence correctly predicted at pixels in non-inundated polygons.

3. False positive (FP) predictions: water presence erroneously predicted at pixels in noninundated polygons.

4. False negative (FN) predictions: water absence erroneously predicted at pixels in inundated polygons.

From the confusion matrix accuracy metrics are retrieved for the homogeneous polygons, as given in Table 2.

In addition, a water detection error (Err) was computed for the heterogeneous (mixed) polygons based on the mean absolute percent error (MAPE), where the area of water observed during field survey (Aw_obs) is compared to the one estimated for the same polygon (Aw_est) (in absolute value) and divided by Aw_obs. The MAPE metric is a widely used scale-independent accuracy measure. The lower the value of MAPE, higher is the accuracy. The water detection error (Err) is thus computed as average over a number of $\mathrm{N}$ observed and non-inundated (Aw_obs different from 0 ) polygons using the following formula: 
Table 2 Definition of the accuracy metrics used for the assessment of the surface-water detection methods.

\begin{tabular}{lc}
\hline \hline OA & $\mathrm{TP}+\mathrm{TN} /(\mathrm{TP}+\mathrm{FP}+\mathrm{TN}+\mathrm{FN})$ \\
\hline Kappa coefficient & $(\operatorname{Pr}(\mathrm{a})-\operatorname{Pr}(\mathrm{e})) /(1-\operatorname{Pr}(\mathrm{e})))^{\mathrm{a}}$ \\
Recall $(R)$ & $\mathrm{TP} /(\mathrm{TP}+\mathrm{FN})$ \\
Precision $(P)$ & $\mathrm{TP} /(\mathrm{TP}+\mathrm{FP})$ \\
\hline \hline
\end{tabular}

${ }^{a} \operatorname{Pr}(\mathrm{a})$ : relative observed agreement, $\operatorname{Pr}(\mathrm{e})$ : hypothetical probability of random agreement.

$$
E r r=\frac{1}{N} \sum_{i=1}^{N} \frac{\left|A w_{\text {obs } \_i}-A w_{\text {est } i}\right|}{A w_{\text {obs } \_i}} .
$$

The water detection error was correlated with parameters that were observed on site (vegetation height, vegetation cover, and water depth) and considered to affect the results.

\section{Results and Discussion}

\subsection{Selection of the Automated Thresholding Method}

Figure 4 shows the pre-processed Sentinel-1 image for the date June 12, 2019 where the backscatter values in decibel range between -34.2 and 26.6. Lower backscatter values (darker tones) are in pixels with water (e.g., rivers, sea, and inundated fields), whereas the highest values (white) appear in settlements and other constructions. In-between backscatter values (gray-level tones) correspond to dry soil, either bare or covered by vegetation. Figure 5 shows the results of the automatic thresholding of the histograms of Sentinel-1 backscatter values using Otsu and Otsu Valley-emphasis algorithms. The threshold value given empirically by a human operator (manual method) is given as a reference threshold value to select the best performing automatic thresholding method. This type of methods is easy to implement and was applied to the six Sentinel-1 images (for exact dates see Fig. 5). The histogram values were normalized.

In all cases shown in Fig. 5, the Otsu Valley-emphasis outperformed the Otsu thresholding method, detecting more accurately the histogram's valley, giving automatically a threshold

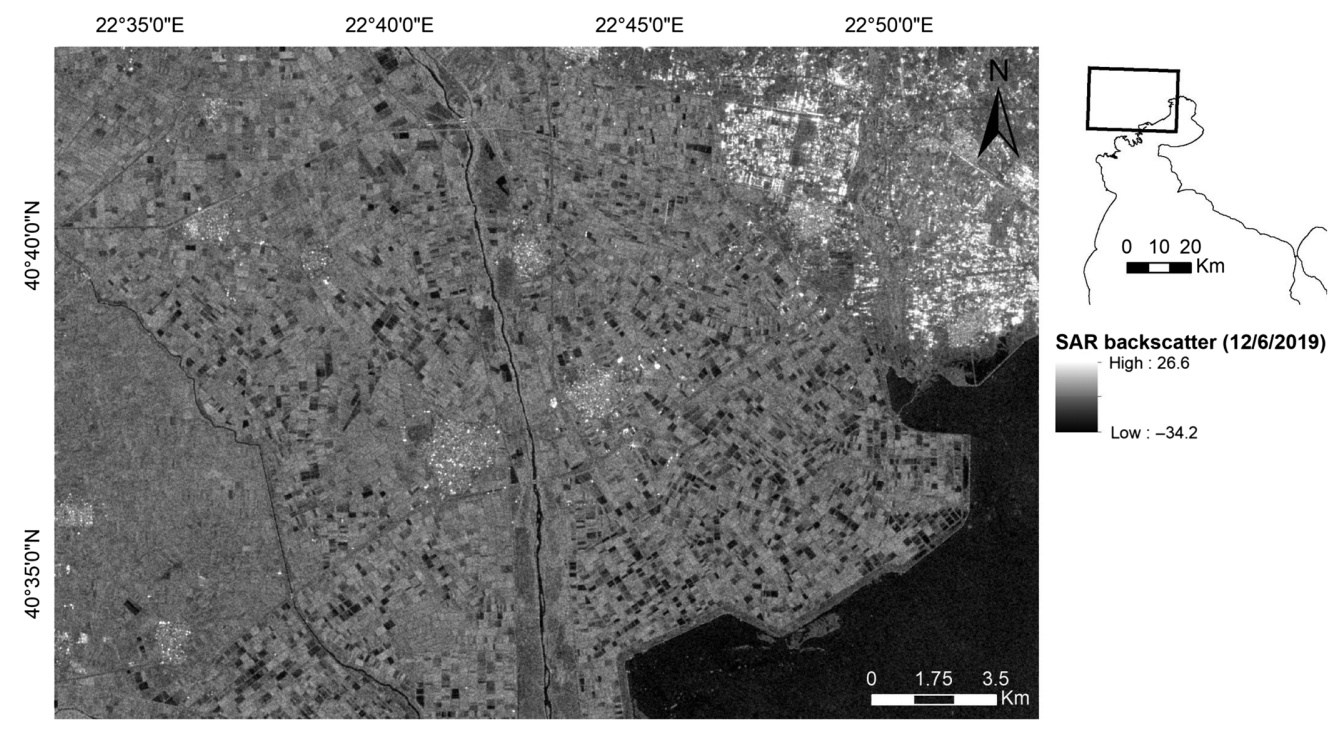

Fig. 4 Pre-processed Sentinel-1 image with backscatter values in decibel for date June 12, 2019. 

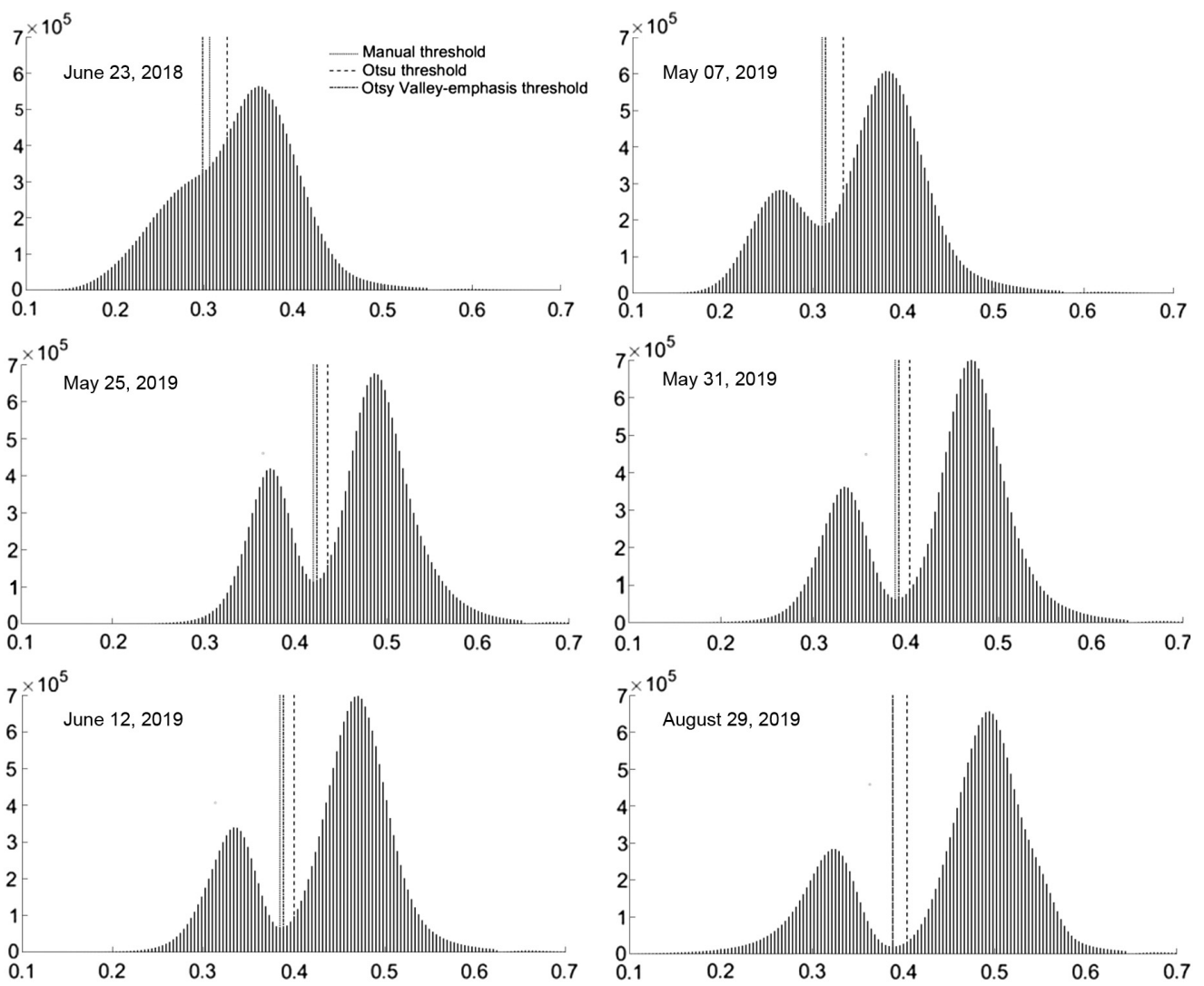

Fig. 5 Normalized backscatter threshold values in Sentinel-1 image histograms for each date for the three methods applied: manual (dotted line), Otsu (dashed line), and Otsu Valley-emphasis (dash-dotted line).

closer to the value provided by a human operator (manual threshold) while on August 29, 2019, the two values coincided. Table 3 gives the water detection accuracy metrics obtained using the manual and automated thresholding methods for one of the dates tested (Sentinel-1 image of June 12, 2019), thus showing the effect of threshold selection on the accuracy of the water maps. The collected in-situ data were used as ground-truth. The Otsu Valley-emphasis method (with a threshold of 0.388) performed much better on June 6, 2019 than the Otsu method (threshold of $0.4)$ with an OA of 0.948 and $P$ of 0.906 for the former and $0.849(\mathrm{OA})$ and $0.657(P)$ for the latter. In addition, it presents an OA value and kappa coefficient close to those obtained with the manual threshold of $0.384(\mathrm{OA}=0.956$, kappa $=0.888)$. Therefore, the Otsu valley-emphasis method was selected as the automated thresholding method to be compared to the rest of the surface-water detection methods.

It should be noted that water mapping using the manual threshold shows the highest $\mathrm{OA}$ and $P$ values in this case but lowest $R$ value, revealing a higher number of FN and the limits of the histogram thresholding approach for separating water from non-water pixels.

Table 3 Summary of accuracy metrics for the three thresholding methods for the date June 12 , 2019.

\begin{tabular}{lcccc}
\hline \hline Method & $P$ & $R$ & OA & Kappa \\
\hline Otsu & 0.657 & 0.929 & 0.849 & 0.662 \\
Otsu Valley-emphasis & 0.906 & 0.903 & 0.948 & 0.869 \\
Manual & 0.941 & 0.896 & 0.956 & 0.888 \\
\hline \hline
\end{tabular}


Table 4 Mean accuracy metrics for all water surface mapping methods for the two dates June 12, 2019, and August 29, 2019.

\begin{tabular}{lcccc}
\hline \hline Method & $\mathrm{OA}$ & $\mathrm{P}$ & $\mathrm{R}$ & Kappa \\
\hline Otsu Valley-emphasis & 0.835 & 0.847 & 0.591 & 0.588 \\
Entropy based & 0.647 & 0.458 & 0.592 & 0.245 \\
Fuzzy rules based & 0.711 & 0.540 & 0.642 & 0.367 \\
K-means based & 0.833 & 0.839 & 0.591 & 0.584 \\
\hline \hline
\end{tabular}

\subsection{Performance of the Water Surface Mapping Methods}

The selected automated thresholding method plus the three other methods presented in Sec. 2.4, were applied on Sentinel-1 images for two characteristic dates: at the beginning of summer when vegetation is low in the rice fields and wetlands are still in inundation (June 12, 2019) and toward the end of the summer when the vegetation is higher in the rice fields and wetlands are drier (August 29, 2019). The accuracy metrics calculated for all methods and both dates are given in Table 4. The results show that the Otsu Valley-emphasis method performs better than the other methods with a mean overall accuracy (OA) of 0.835 and kappa coefficient of 0.588 . A slightly lower OA is obtained with the method based on $K$-means classification $(\mathrm{OA}=0.833$, kappa 0.584). However, the fact that the method does not systematically classify the water-related pixels into the same cluster between different dates of application, makes it impossible to have it fully automated and used operationally. The other two methods (entropy-based and fuzzy rulesbased) present much lower accuracy metrics (OA, $P$, kappa), whereas the $R$ values for all methods are very close.

When considering the accuracy metrics obtained for single dates the OA ranges from 0.504 to 0.948. The Otsu Valley-emphasis was found to be the most accurate method for each date $(0.948$ on June 12, 2019 and 0.723 on August 29, 2019). The detailed analysis of the results per date showed that for all methods the accuracy was lower toward the end of the summer (August 29, 2019) compared to the beginning of the same season (June 12, 2019). By analyzing specific examples where the methods failed to correctly detect water, it appears that this was due to the presence of high and dense inundated vegetation, which covers water and affects the recall in the Sentinel-1 images. $^{24}$

\subsection{Application and Assessment of the Otsu Valley-Emphasis Method During the May-June Period}

Due to its ease of automation and its higher performance, the Otsu Valley-emphasis method was selected and further tested. The method was used to produce water maps for the period of MayJune, which is the most critical period for larvicide application in rice fields and wetlands. Data for five dates were used for this purpose: June 23, 2018, May 07, 2019, May 25, 2019, May 31, 2019, and June 12, 2019 (see Table 1 for details over the number and land cover type of sampling polygons).

\subsubsection{Overall evaluation of the Otsu Valley-emphasis method}

To carry out the assessment, all available sampling data from homogeneous polygons for the May-June period of years 2018 and 2019 were used. According to Table 5, the OA for all dates was found to be 0.862 , indicating that the algorithm detects water presence with a systematic high accuracy.

Figure 6 shows the surface-water maps obtained for these dates. Except for the river Axios and coastal lagoons that were inundated throughout the May-June period, the temporal variations between the examined dates show the flood irrigation events on rice fields. 
Table 5 Confusion matrix for the Otsu Valley-emphasis method in the May-June period.

\begin{tabular}{lccccccc}
\hline \hline & \multicolumn{3}{c}{ Observations (in pixels) } & & & & \\
\cline { 2 - 6 } Predictions & $\begin{array}{l}\text { Absence } \\
\text { of water }\end{array}$ & $\begin{array}{c}\text { Presence } \\
\text { of water }\end{array}$ & Total & $P$ & $R$ & OA & Kappa \\
\hline Absence of water & 39893 & 4229 & 44122 & 0.822 & 0.900 & 0.862 & 0.725 \\
Presence of water & 8225 & 38108 & 46333 & & & & \\
Total & 48118 & 42337 & 90455 & & & & \\
\hline \hline
\end{tabular}

To better interpret the water mapping results TN, TP, FN, and FP are shown on a map for the date May 31, 2019. Figure 7 shows cases where the algorithm failed to identify the inundated areas with FN predictions, which were located mainly on the fringe of the Kalochori lagoon. The inundated wetlands had a depth between 30 and $100 \mathrm{~cm}$ but without vegetation. Some birds were observed during field survey that explain some of the FN predictions in the center of the polygons. There are also cases where the algorithm detects water presence in areas that are

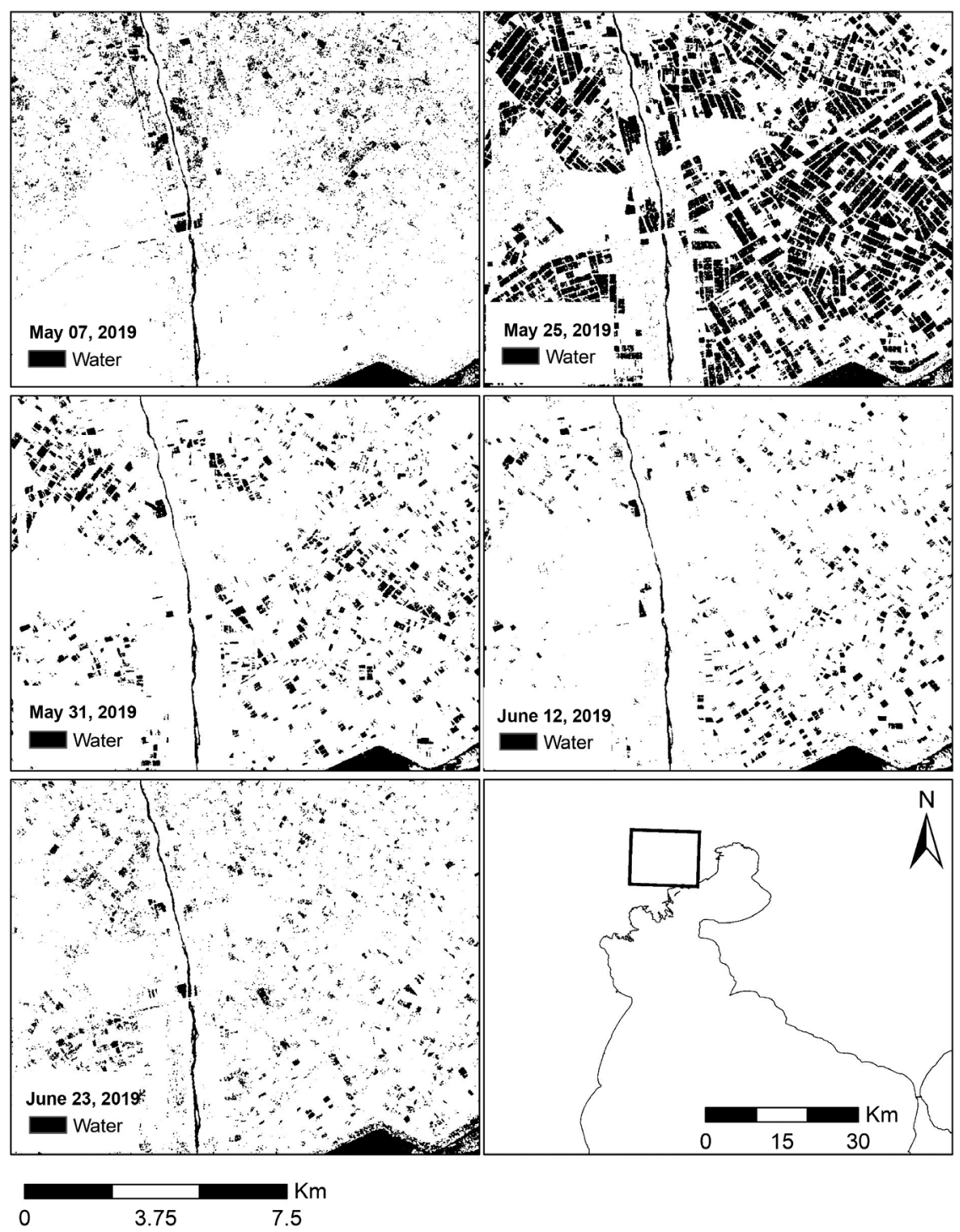

Fig. 6 Maps of surface-water bodies using the Otsu Valley-emphasis method during the period of May-June for the years 2018 and 2019. 


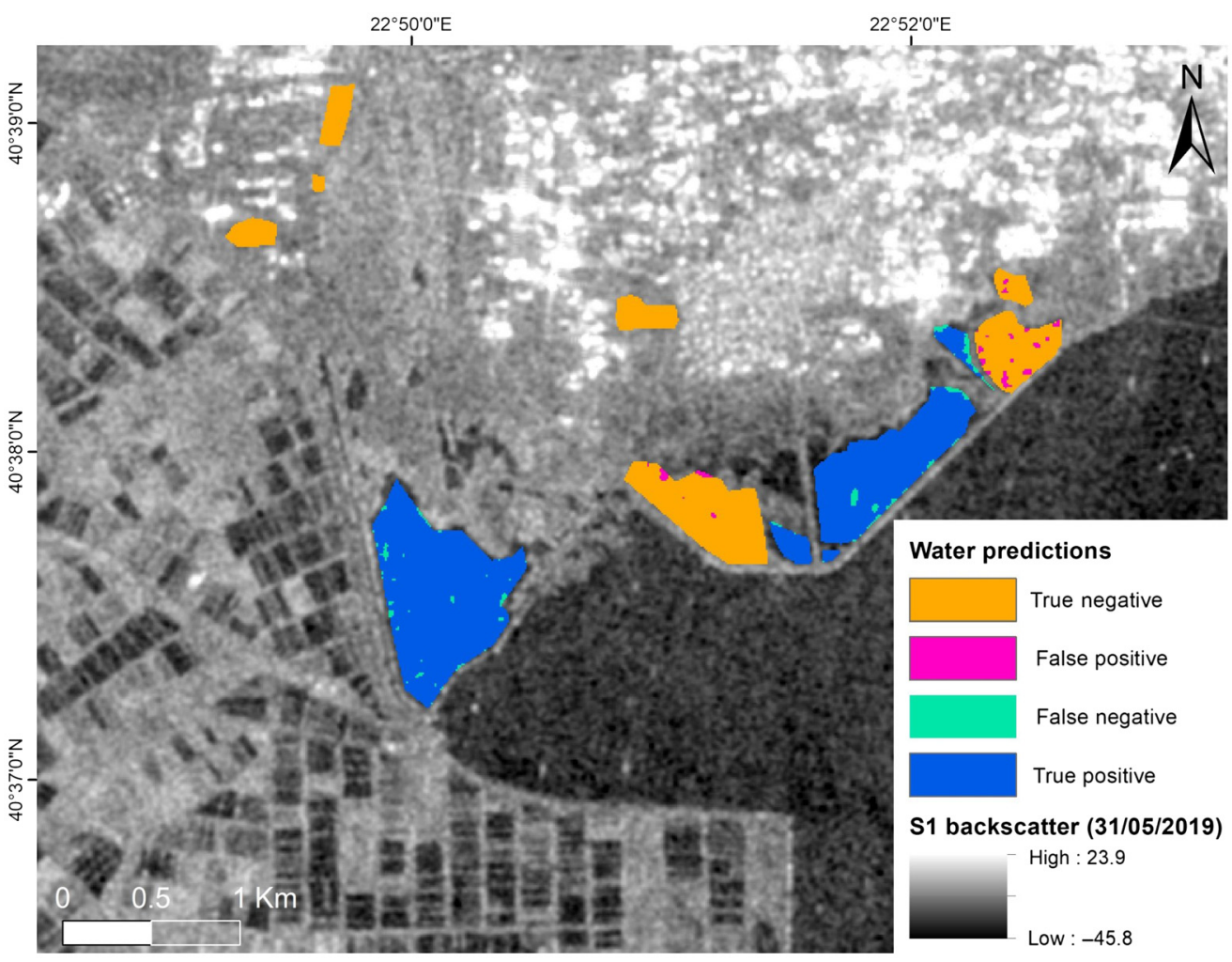

Fig. 7 Examples of FN (light green) and FP (pink) predictions for the date May 31, 2019.

non-inundated (FP predictions), which were scattered around the coastal grasslands of Kalochori where vegetation was estimated to cover $80 \%$ of the polygons. The FP predictions found for the dry wetland in the eastern part of Fig. 7 were due to the presence of roads as reported during field survey.

\subsubsection{Impact of land use type}

Results were further analyzed by dividing the data according to their land use type into rice fields and wetlands. The confusion matrix in Table 6 shows separately for rice fields and wetlands the surface-water bodies mapping results during the period of May-June for the years 2018 and 2019. Due to the extent of wetlands there are much more ground-truth pixels in wetlands than in rice fields. The OA was 0.854 in wetlands and 0.915 in rice fields. The lower accuracy in rice fields is due to the small size of the fields, the lower water depth when they are inundated and the presence of vegetation.

Table 6 Confusion matrix according to land use for the period of May-June (2018 and 2019).

\begin{tabular}{|c|c|c|c|c|c|c|c|c|}
\hline \multirow[b]{2}{*}{ Land cover } & \multicolumn{4}{|c|}{ Observations (in pixels) } & \multirow[b]{2}{*}{$P$} & \multirow[b]{2}{*}{$R$} & \multirow[b]{2}{*}{ OA } & \multirow[b]{2}{*}{ Kappa } \\
\hline & Predictions & $\begin{array}{l}\text { Absence } \\
\text { of water }\end{array}$ & $\begin{array}{l}\text { Presence } \\
\text { of water }\end{array}$ & Total & & & & \\
\hline \multirow[t]{2}{*}{ Rice fields } & $\begin{array}{l}\text { Absence of water } \\
\text { Presence of water }\end{array}$ & $\begin{array}{l}7660 \\
27\end{array}$ & $\begin{array}{l}1023 \\
3584\end{array}$ & $\begin{array}{l}8683 \\
3611\end{array}$ & 0.882 & 0.778 & 0.915 & 0.809 \\
\hline & Total & 7687 & 4607 & 12294 & & & & \\
\hline \multirow[t]{2}{*}{ Wetlands } & $\begin{array}{l}\text { Absence of water } \\
\text { Presence of water }\end{array}$ & $\begin{array}{l}32233 \\
8198\end{array}$ & $\begin{array}{c}3206 \\
34524\end{array}$ & $\begin{array}{l}35439 \\
42722\end{array}$ & 0.910 & 0.915 & 0.854 & 0.709 \\
\hline & Total & 40431 & 37730 & 78161 & & & & \\
\hline
\end{tabular}




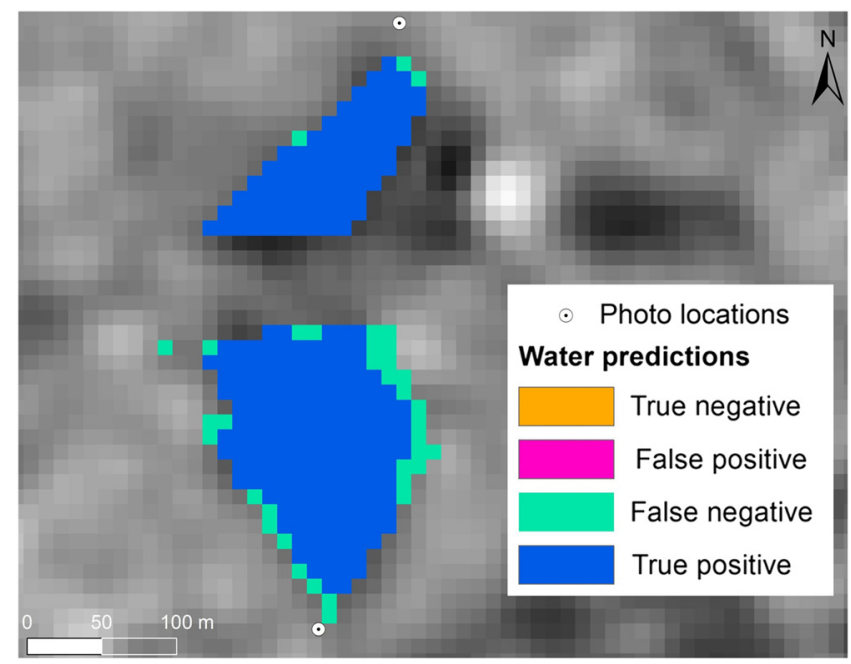

Fig. 8 FN predictions (light green color) perimetrically of rice polygons on May 25, 2019.

For both rice fields and wetlands, the pixels were in most cases classified as TN or TP predictions. This means that the presence or absence of water was correctly detected. There are few cases where the method failed to predict water presence $(\mathrm{FN})$ or predicted water in dry areas (FP). However, the recall and precision values are considered satisfactory $(R=0.778$ and $P=$ 0.882 in rice fields and $R=0.915$ and $P=0.910$ in wetlands).

Concerning the rice fields, in most cases where the method failed, the pixels were located at the perimeter of the polygons (see Fig. 8). This could be explained by the larger slopes usually found perimetrically of the fields due to the insufficient leveling of rice paddies at the beginning of the growing season, resulting in a higher concentration of water toward the center of the fields. In addition, the presence of floating algae (of green or brown color) and its concentration perimetrically of the parcels (see Fig. 9) increased the roughness of water thus increased the backscatter value to levels closer to that of vegetation. The erroneous predictions due to presence of floating vegetation in fields have also been documented by Hardy et al. ${ }^{24}$ The main reasons contributing to the presence of floating algae in rice fields related mainly to the cultivation practices followed by farmers (including continuous rice growing without crop rotation), and its subsequent extensive use of nitrogen fertilizers. ${ }^{44}$

The presence of water was not fully detected in some polygons with rice, possibly due to the presence of inundated vegetation. This was noticed in the mixed field survey polygons to where for example the polygon in Fig. 10 was found during fieldwork on June 12, 2019, to be 90\% covered by water, whereas $70 \%$ of the polygon area was covered by vegetation of $15 \mathrm{~cm}$ height,
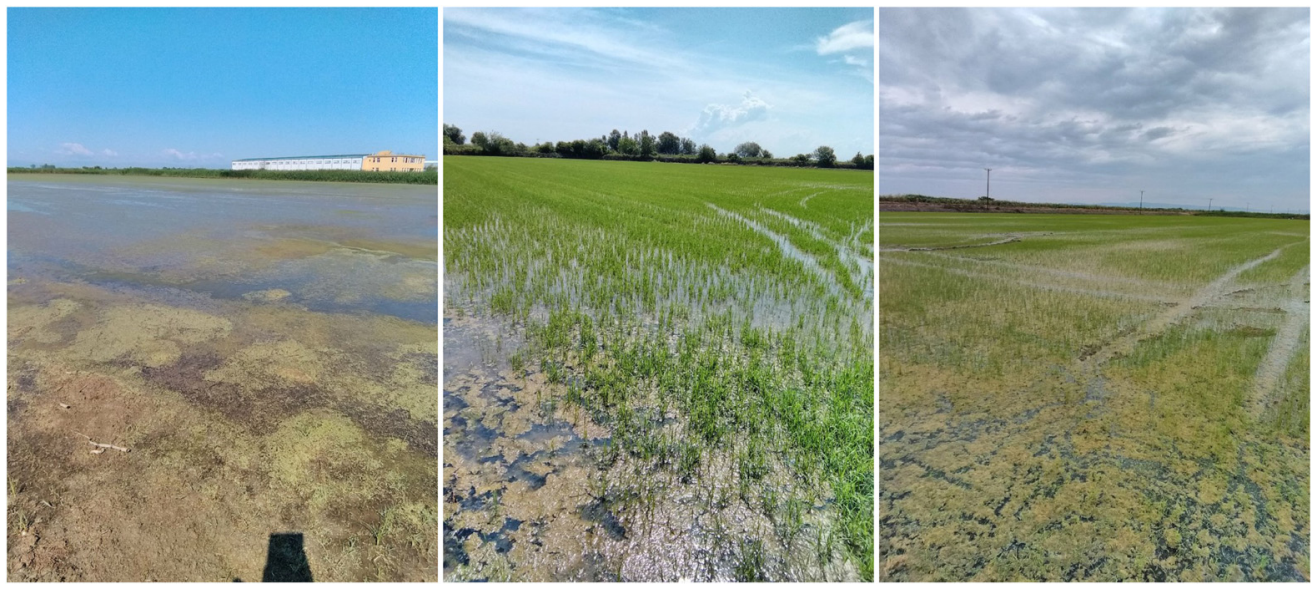

Fig. 9 Rice field photographs of FN predictions due to the presence of floating algae. 

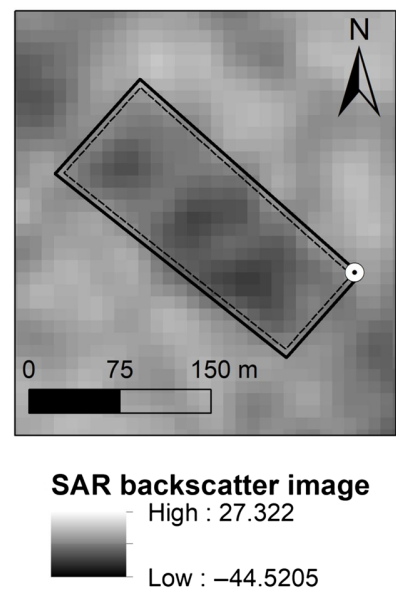

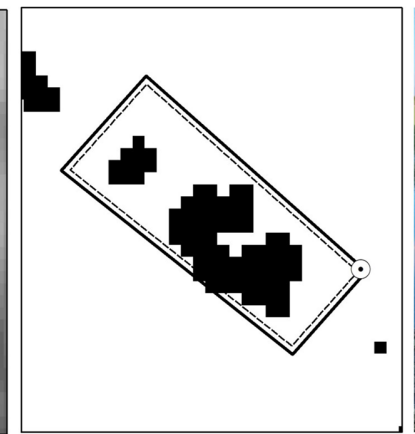

Water map (June 12, 2019) Water

Fig. 10 Example of FN predictions in a mixed in-situ rice field polygon.

and the algorithm estimated only $37.86 \%$ of the total polygon area to be inundated. The error in predicting the presence of water (Err) in this case was 0.638 .

The results of water presence mapping in wetlands were evaluated as satisfactory. Figure 11 shows examples of FP predictions in wetlands. These were mainly due to the presence of buildings and stables, and due to the presence of mixed land uses (e.g., the presence of rural roads at the borders of polygons) and surface salt crust formations on the soil surface (see Fig. 12). Salt crust formations are incorrectly captured by the SAR sensor as water bodies due to their high electrical conductivity, which causes higher backscatter in a manner that resembles water surfaces. ${ }^{45,46}$ Inspection in the field showed that salt-crusts presence is usually limited to salt marshes along the coastline forming relatively narrow strips that do not significantly affect the mapping of water surfaces. In addition, built-up areas that were causing erroneous predictions were identified in the field to be limited to individual rural installations, whereas urban areas reported as a known source of false alarms in relevant literature ${ }^{47,48}$ were masked off the final maps.

The assessment of the map of surface-water bodies on June 12, 2019, in sampling polygons of other types of crops (except rice fields) showed mostly TN predictions in dry cotton fields (three cases in total) and dry corn fields (nine cases in total). The water detection errors (Err) found during the analysis of all SAR images ranged between 0.0017 and 1 in all polygons
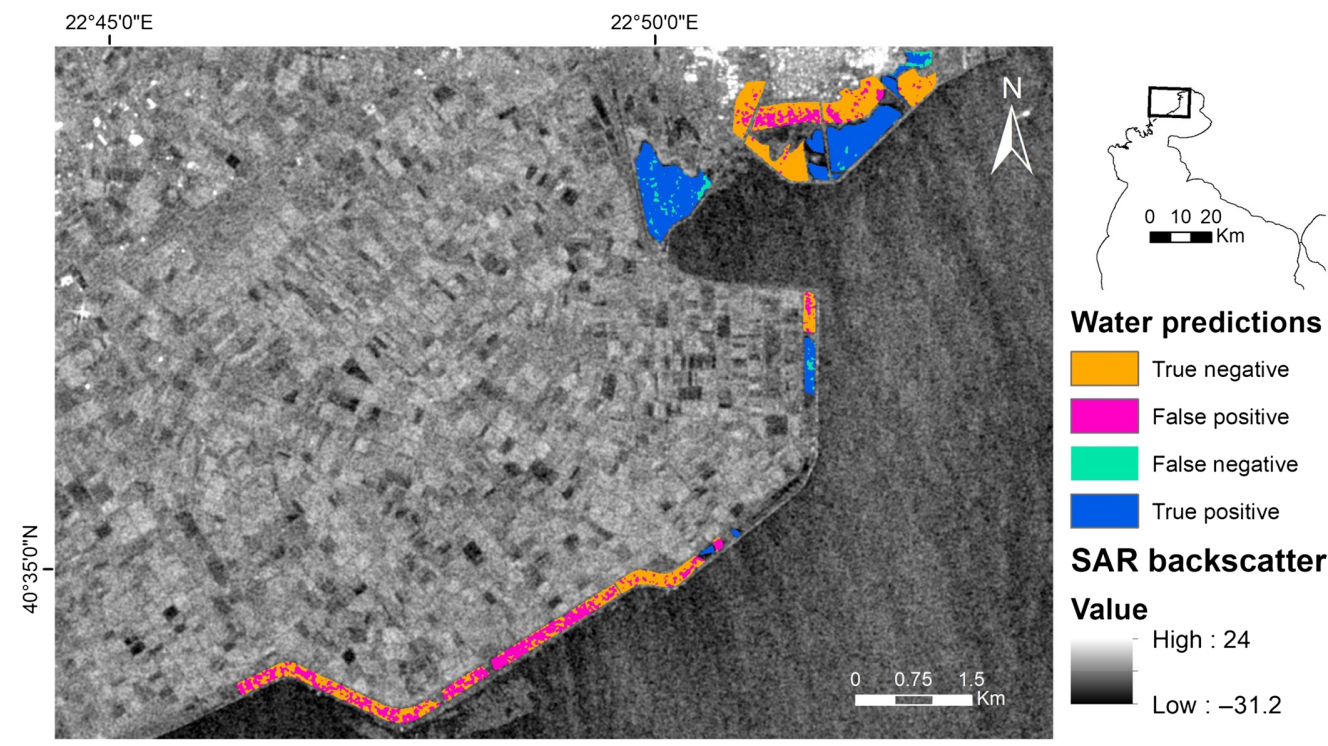

Water predictions

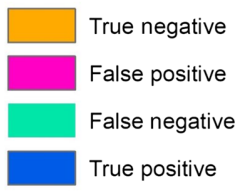

SAR backscatter

Value

High : 24
Low : -31.2

Fig. 11 Examples of FP predictions in wetlands on June 23, 2018. 

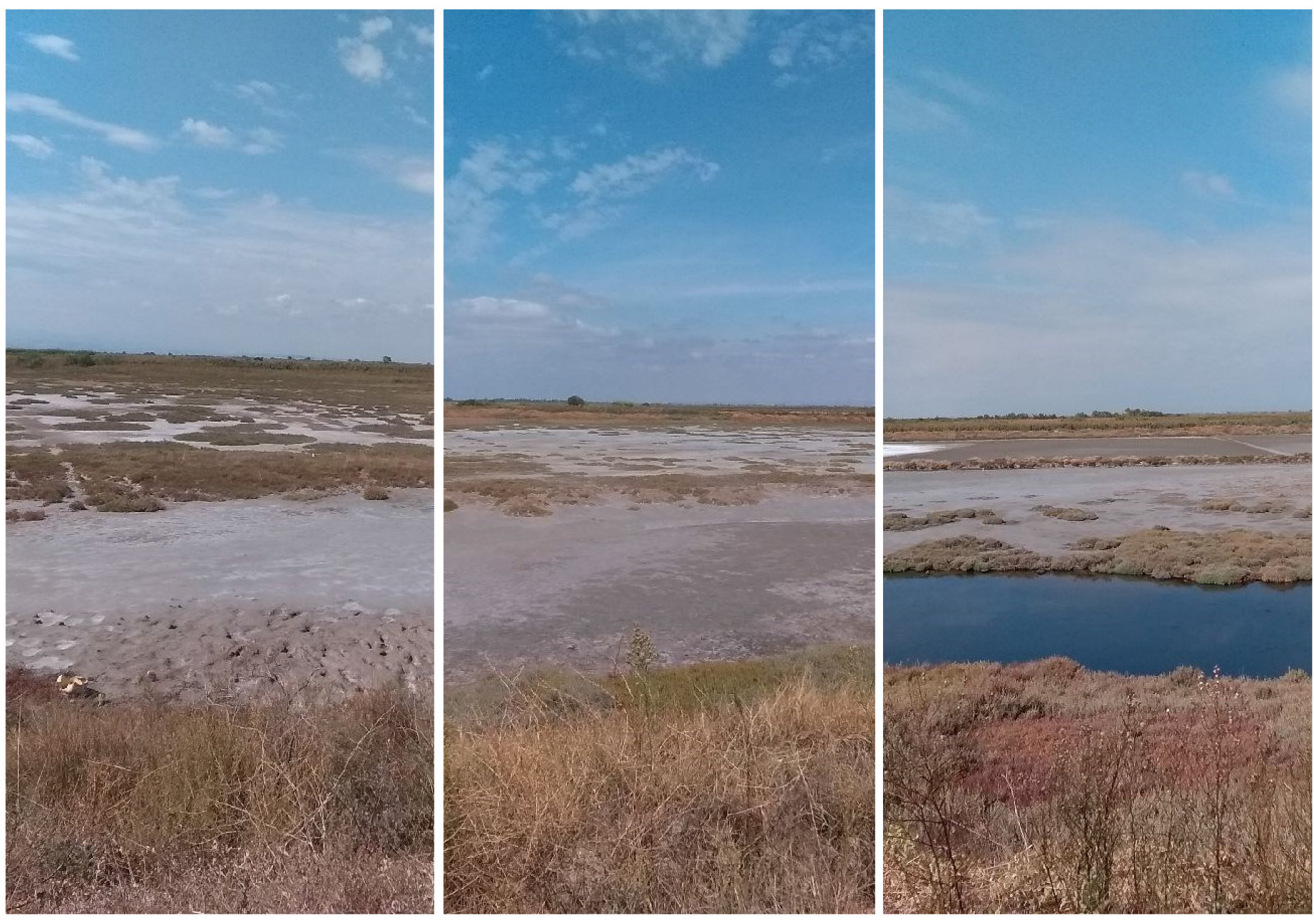

Fig. 12 Salt crusts on soil surface of sampling polygons of wetlands.

examined, whereas in a single case the error was 1.99 . The average error value for rice paddies was 0.709 , whereas for wetlands it was 0.459 .

\subsubsection{Impact of inundated vegetation}

The effect of inundated vegetation presence in the detection of surface-water bodies was analyzed separately for wetlands and rice fields, dividing the sampling polygons into two categories;

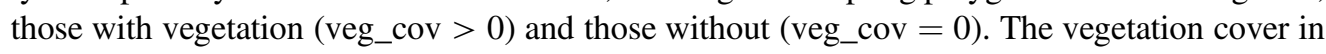
both cases ranges from $0 \%$ to $100 \%$. Tables 7 and 8 gives the resulting confusion matrices, which shows that the OA was higher in the case of absence of vegetation cover $(0.965$ in rice fields instead of 0.847 and 0.962 instead of 0.824 in wetlands). Since no samples were collected without vegetation cover and in absence of water in wetlands as shown in Table 8, the accuracy metrics in wetlands should be interpreted with care. In rice fields though, it is clear from Table 7 that $R$ is lower in the presence of vegetation cover $(R=0.578$ against 0.918 in non-vegetated areas) indicating a higher number of FN predictions. In addition, the correlation

Table 7 Confusion matrices according to the vegetation cover in the rice fields in the period of May-June (2018 and 2019).

\begin{tabular}{|c|c|c|c|c|c|c|c|c|}
\hline \multirow[b]{2}{*}{$\begin{array}{l}\text { Vegetation } \\
\text { cover (\%) }\end{array}$} & \multicolumn{4}{|c|}{ Observations (in pixels) } & \multirow[b]{2}{*}{$P$} & \multirow[b]{2}{*}{$R$} & \multirow[b]{2}{*}{ OA } & \multirow[b]{2}{*}{ Kappa } \\
\hline & Predictions & $\begin{array}{l}\text { Absence } \\
\text { of water }\end{array}$ & $\begin{array}{l}\text { Presence } \\
\text { of water }\end{array}$ & Total & & & & \\
\hline \multirow[t]{2}{*}{ veg_cov $=0$} & $\begin{array}{l}\text { Absence of water } \\
\text { Presence of water }\end{array}$ & $\begin{array}{c}4321 \\
25\end{array}$ & $\begin{array}{c}221 \\
2487\end{array}$ & $\begin{array}{l}4542 \\
2512\end{array}$ & 0.990 & 0.918 & 0.965 & 0.925 \\
\hline & Total & 4346 & 2708 & 7054 & & & & \\
\hline \multirow[t]{2}{*}{ veg_cov >0 } & $\begin{array}{l}\text { Absence of water } \\
\text { Presence of water }\end{array}$ & $\begin{array}{c}3339 \\
2\end{array}$ & $\begin{array}{c}802 \\
1097\end{array}$ & $\begin{array}{l}4141 \\
1099\end{array}$ & 0.998 & 0.578 & 0.847 & 0.635 \\
\hline & Total & 3341 & 1899 & 5240 & & & & \\
\hline
\end{tabular}


Table 8 Confusion matrices according to the vegetation cover in the wetlands in the period of May-June (2018 and 2019).

\begin{tabular}{llccccccc}
\hline \hline & \multicolumn{9}{c}{ Observations (in pixels) } \\
\cline { 2 - 7 } $\begin{array}{l}\text { Vegetation } \\
\text { growth (\%) }\end{array}$ & \multicolumn{1}{c}{ Predictions } & $\begin{array}{c}\text { Absence } \\
\text { of water }\end{array}$ & $\begin{array}{c}\text { Presence } \\
\text { of water }\end{array}$ & Total & $P$ & $R$ & OA & Kappa \\
\hline veg_cov $=0$ & Absence of water & 0 & 646 & 646 & - & 0.962 & 0.962 & - \\
& Presence of water & 0 & 16528 & 16528 & & & & \\
& Total & 0 & 17174 & 17174 & & & & \\
veg_cov $>0$ & Absence of water & 32233 & 2560 & 34793 & 0.687 & 0.875 & 0.824 & 0.630 \\
& Presence of water & 8198 & 17996 & 26194 & & & & \\
& Total & 40431 & 20556 & 60987 & & & & \\
\hline \hline
\end{tabular}

analysis of the water detection errors (Err) against the vegetation cover showed that there is a statistically significant positive correlation between the error in the estimation of the inundated areas and the percentage of vegetation cover within a polygon $(r=0.75, p$-value $<0.001)$, whereas a lower correlation $(r=0.34, p$-value $=0.0001)$ was found between Err and the vegetation height. In the case of wetlands with no vegetation cover, the kappa coefficient was zero, due to the lack of available samples. The impact of inundated vegetation on algorithms of water detection is well-documented in relevant literature. ${ }^{49-51}$ In addition, such errors are also reported due to the presence of mixed water-vegetation pixels. ${ }^{50}$

\subsubsection{Impact of water depth}

An analysis of the OA according to the water depth was also performed separately for rice fields and wetlands, with water depth classes ranging from 0 (no surface-water) to $10 \mathrm{~cm}$ for rice fields, and from 0 to $65 \mathrm{~cm}$ for wetlands. Tables 9 and 10 gives the confusion matrices for each case. For both wetland systems and rice fields, the OA is lower for shallow water depths (except for the no surface-water case where $d=0$ ) and increases with the depth to reach 0.894 in the case of rice and 0.948 in the case of wetlands. The coefficient of correlation between the water detection error (Err) and the water depth in the sampling polygons is $r=-0.46$ ( $p$-value $<0.001$ ), indicating a negative correlation, where the error decreases as the water depth increases. At shallow water depths the accuracy of the water detection algorithm was low ( 0.655 in rice fields and 0.625 in wetlands) and increased with the water depth reaching up to 0.948 in wetland areas

Table 9 Confusion matrices according to water depth in the rice fields in the period of May-June (2018 and 2019).

\begin{tabular}{|c|c|c|c|c|c|c|c|}
\hline \multirow[b]{2}{*}{ Water depth } & \multicolumn{4}{|c|}{ Observations (in pixels) } & \multirow[b]{2}{*}{$P$} & \multirow[b]{2}{*}{$R$} & \multirow[b]{2}{*}{$\mathrm{OA}$} \\
\hline & Predictions & $\begin{array}{l}\text { Absence } \\
\text { of water }\end{array}$ & $\begin{array}{c}\text { Presence } \\
\text { of water }\end{array}$ & Total & & & \\
\hline \multirow[t]{3}{*}{$d=0$} & Absence of water & 7660 & 0 & 7660 & - & - & 0.996 \\
\hline & Presence of water & 27 & 0 & 27 & & & \\
\hline & Total & 7687 & 0 & 7687 & & & \\
\hline \multirow[t]{3}{*}{$0<d<=5$} & Absence of water & 0 & 772 & 772 & - & 0.655 & 0.655 \\
\hline & Presence of water & 0 & 1467 & 1467 & & & \\
\hline & Total & 0 & 2239 & 2239 & & & \\
\hline \multirow[t]{3}{*}{$5<d<=10$} & Absence of water & 0 & 251 & 251 & - & 0.894 & 0.894 \\
\hline & Presence of water & 0 & 2117 & 2117 & & & \\
\hline & Total & 0 & 2368 & 2368 & & & \\
\hline
\end{tabular}


Table 10 Confusion matrix according to water depth in the wetlands in the period of May-June (2018 and 2019).

\begin{tabular}{|c|c|c|c|c|c|c|c|}
\hline \multirow[b]{2}{*}{ Water depth } & \multicolumn{4}{|c|}{ Observations (in pixels) } & \multirow[b]{2}{*}{$P$} & \multirow[b]{2}{*}{$R$} & \multirow[b]{2}{*}{ OA } \\
\hline & Predictions & $\begin{array}{l}\text { Absence } \\
\text { of water }\end{array}$ & $\begin{array}{l}\text { Presence } \\
\text { of water }\end{array}$ & Total & & & \\
\hline \multirow[t]{2}{*}{$d=0$} & $\begin{array}{l}\text { Absence of water } \\
\text { Presence of water }\end{array}$ & $\begin{array}{l}32233 \\
8198\end{array}$ & $\begin{array}{l}0 \\
0\end{array}$ & $\begin{array}{c}32233 \\
8198\end{array}$ & - & - & 0.797 \\
\hline & Total & 40431 & 0 & 40431 & & & \\
\hline \multirow[t]{2}{*}{$0<d<=20$} & $\begin{array}{l}\text { Absence of water } \\
\text { Presence of water }\end{array}$ & $\begin{array}{l}0 \\
0\end{array}$ & $\begin{array}{l}524 \\
874\end{array}$ & $\begin{array}{l}524 \\
874\end{array}$ & - & 0.625 & 0.625 \\
\hline & Total & 0 & 1398 & 1398 & & & \\
\hline \multirow[t]{2}{*}{$20<d<=50$} & $\begin{array}{l}\text { Absence of water } \\
\text { Presence of water }\end{array}$ & $\begin{array}{l}0 \\
0\end{array}$ & $\begin{array}{l}1190 \\
6561\end{array}$ & $\begin{array}{l}1190 \\
6561\end{array}$ & - & 0.846 & 0.846 \\
\hline & Total & 0 & 7751 & 7751 & & & \\
\hline \multirow[t]{2}{*}{$50<d$} & $\begin{array}{l}\text { Absence of water } \\
\text { Presence of water }\end{array}$ & $\begin{array}{l}0 \\
0\end{array}$ & $\begin{array}{c}1492 \\
27089\end{array}$ & $\begin{array}{c}1492 \\
27089\end{array}$ & - & 0.948 & 0.948 \\
\hline & Total & 0 & 28581 & 28581 & & & \\
\hline
\end{tabular}

deeper than $50 \mathrm{~cm}$. The recall value also increased at greater depths. The water depth in the rice fields did not exceed $10 \mathrm{~cm}$ when the fields were flooded. The correlation between the water detection error and the water depth in the sampling polygons showed a negative correlation, where the error decreases as the water depth increases, which is in line with the findings of Caballero and Stumpf ${ }^{52}$ and Martinis et al. ${ }^{22}$

\subsection{WebGIS Development for the Dissemination of the Produced Water Maps}

A WebGIS platform was developed for the dissemination of the surface-water bodies mapping results together with other relevant data important for the prediction of mosquito larvae presence (e.g., presence of vegetation, vegetation characteristics, and historical sampling data of larvae presence in specified areas, platform can be accessed through Ref. 53. The WebGIS as shown in Fig. 13 was designed using the functionalities of the ArcGIS Online platform. The WebGIS

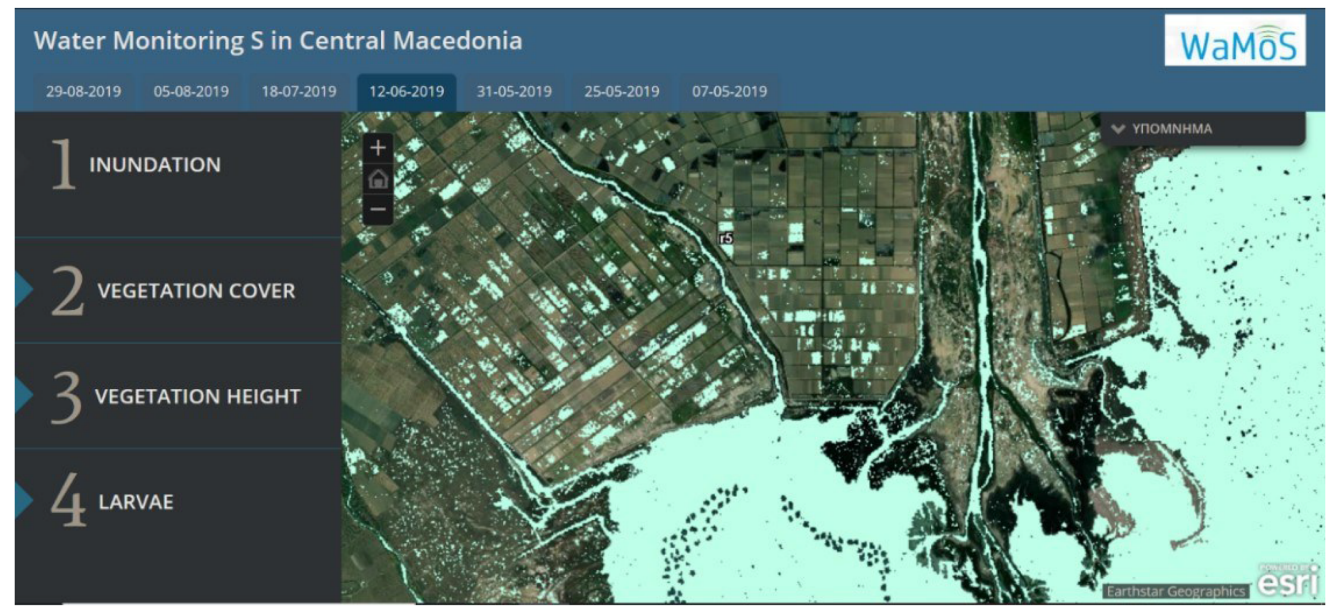

Fig. 13 Preview of the WebGIS platform created for the visualization of the surface-water mapping results for specific dates. Water presence is indicated with light green color. 
includes the existing results from surface-water detection, and field surveyed data for vegetation cover, vegetation height, water depth, larvae abundance, and species. Later, it will integrate the results from the operational use of the surface-water detection algorithm using the Otsu Valleyemphasis thresholding method. The maps will be available for past dates and in NRT for new dates for the region of Central Macedonia, Greece.

\section{Conclusions}

Various methodologies for the automatic mapping of surface-water bodies in rice fields and wetland systems were adapted and tested. Comparison and evaluation of the methods were performed using field data for the period 2018-2019. The highest OA in detecting inundated areas using two characteristic dates (beginning and end of summer season) was achieved with the Otsu Valleyemphasis method (0.835). This method detects automatically from a SAR backscatter histogram the threshold value indicating the presence of water. An OA of 0.862 was obtained by the same method during the larvicide application method during, which the algorithm was further tested. More specifically, an OA of 0.915 in rice fields and 0.854 in wetland systems were recorded during the period May-June of the years 2018 and 2019. The identified sources of water mapping errors are mainly related to the presence of flooded vegetation and the water depth of water bodies, the presence of buildings and agricultural facilities (e.g., stables and greenhouses), and the presence of floating algae in rice fields and of surface salt crusts in wetland systems. As a result, an operational and automated approach was proposed for the systematic (every six days) identification of surfacewater bodies through high spatial resolution SAR data (Sentinel-1) in NRT. A WebGIS platform was designed for the continuous monitoring of surface-water bodies and the identification of habitats favoring mosquito algae breeding where all produced maps are made accessible and new maps will be uploaded in NRT. In addition, the resulting maps will be incorporated in a spatial decision support system to facilitate effective control of mosquito larvae.

\section{Acknowledgments}

This work has been co-financed by the European Regional Development Fund of the European Union and Greek national funds through the Operational Program Competitiveness, Entrepreneurship, and Innovation, under the call RESEARCH - CREATE - INNOVATE (project code: T1EDK-05106). All data were processed within the project "WaMoS: Monitoring of surface-waters with remote sensing for the rational use of insecticides in wide area mosquito control." Sentinel-1 data were provided by the ESA. ${ }^{23}$ Conflicts of interest: No potential competing interest was reported by the authors.

\section{References}

1. M. S. Sarfraz et al., "Mapping urban and peri-urban breeding habitats of Aedes mosquitoes using a fuzzy analytical hierarchical process based on climatic and physical parameters," Geospatial Health. 8, S685-S697 (2014).

2. M. L. Schäfer and J. O. Lundström, "Detection of temporary flooded areas with potential floodwater mosquito production using imaging radar,' Int. J. Remote Sens. 33(6), 19431953 (2012).

3. S. Gewehr, N. Piakis-Chatzievagelou, and S. Mourelatos, "Ecological mapping: the use of Geographic Information Systems (GIS) for rational mosquito control in natural wetlands," J. Environ. Prot. Ecol. 7(3), 617-625 (2006).

4. E. De Roeck et al., "Fine-scale mapping of vector habitats using very high resolution satellite imagery: a liver fluke case-study," Geospatial Health 8, S671-S683 (2014).

5. S. Mourelatos et al., "The use of Sentinel 1 SAR imagery for wide area mosquito control," in E-SOVE 20th Conf., Lisboa (2016).

6. G. Ovakoglou et al., "Use of MODIS satellite images for detailed lake morphometry: application to basins with large water level fluctuations," Int. J. Appl. Earth Obs. Geoinf. 51, 37-46 (2016). 
7. Y. Chemin and U. Rabbani, "A new methodology for virtual water level gauges," Int. J. Geoinf. 12(1), 15-25 (2016).

8. J. Lacaux et al., "Classification of ponds from high-spatial resolution remote sensing: application to Rift Valley Fever epidemics in Senegal," Remote Sens. Environ. 106(1), 66-74 (2007).

9. P. Dambach et al., "Using high spatial resolution remote sensing for risk mapping of malaria occurrence in the Nouna district, Burkina Faso," Global Health Action 2(1), 2094 (2009).

10. C. Vignolles et al., "Re-emerging malaria vectors in rural Sahel (Nouna, Burkina Faso): the Paluclim project," Int. Arch. Photogramm. Remote Sens. Spatial Inf. Sci. XLI-B8, 237-242 (2016).

11. S. K. McFeeters, "The use of the Normalized Difference Water Index (NDWI) in the delineation of open water features," Int. J. Remote Sens. 17(7), 1425-1432 (1996).

12. V. Machault et al., "Risk mapping of Anopheles gambiae s.l densities using remotely-sensed environmental and meteorological data in an urban area: Dakar, Senegal," PLoS One 7(11), e50674 (2012).

13. C. Huang et al., "A comparison of terrain indices toward their ability in assisting surface water mapping from Sentinel-1 data," ISPRS Int. J. Geo-Inf. 6(5), 140 (2017).

14. Y.-S. Song, H.-G. Sohn, and C.-H. Park, "Efficient water area classification using Radarsat1 SAR imagery in a high relief mountainous environment," Photogramm. Eng. Remote Sens. 73(3), 285-296 (2007).

15. A. Nelson et al., "Towards an operational SAR-based rice monitoring system in Asia: examples from 13 demonstration sites across Asia in the RIICE project," Remote Sens. 6(11), 10773-10812 (2014).

16. J. Betbeder et al., "Multitemporal classification of TerraSAR-X data for wetland vegetation mapping," J. Appl. Remote Sens. 8(1), 083648 (2014).

17. J. Mohite et al., "Operational near real time rice area mapping using multi-temporal Sentinel-1 SAR observations," Int. Arch. Photogramm. Remote Sens. Spatial Inf. Sci. XLII-4(4), 433-438 (2018).

18. C. Vignolles et al., "TerraSAR-X high-resolution radar remote sensing: an operational warning system for Rift Valley fever risk," Geospatial Health 5(1), 23-31 (2010).

19. L. L. Bourgeau-Chavez et al., "Remote monitoring of spatial and temporal surface soil moisture in fire disturbed boreal forest ecosystems with ERS SAR imagery," Int. J. Remote Sens. 28(10), 2133-2162 (2007).

20. J. B. Henry et al., "Envisat multi-polarized ASAR data for flood mapping," Int. J. Remote Sens. 27(10), 1921-1929 (2006).

21. A. Twele et al., "Sentinel-1-based flood mapping: a fully automated processing chain," Int. J. Remote Sens. 37(13), 2990-3004 (2016).

22. S. Martinis, J. Kersten, and A. Twele, "A fully automated TerraSAR-X based flood service," ISPRS J. Photogramm. Remote Sens. 104, 203-212 (2015).

23. European Space Agency, Copernicus Open Access Hub, ESA 2014-2021, https://scihub .copernicus.eu/dhus/\#/home (access 4 February 2021).

24. A. Hardy et al., "Automatic detection of open and vegetated water bodies using Sentinel 1 to map African Malaria vector mosquito breeding habitats," Remote Sens. 11(5), 593 (2019).

25. F. Bioresita et al., "A method for automatic and rapid mapping of water surfaces from sentinel-1 imagery," Remote Sens. 10(2), 217 (2018).

26. D. Amitrano et al., "Unsupervised rapid flood mapping using Sentinel-1 GRD SAR images," IEEE Trans. Geosci. Remote Sens. 56(6), 3290-3299 (2018).

27. S. Martinis, "Improving flood mapping in arid areas using Sentinel-1 time series data," in IEEE Int. Geosci. Remote Sens. Symp., IEEE, p. 193-196 (2017).

28. N. Gorelick et al., "Google Earth Engine: planetary-scale geospatial analysis for everyone," Remote Sensing of Environment, https://developers.google.com/earth-engine/sentinel1 (access 4 February 2021).

29. J.-S. Lee, "Digital image smoothing and the sigma filter," Comput. Vision, Graphics Image Process. 24(2), 255-269 (1983). 
30. P. Singh and R. Shree, "Analysis and effects of speckle noise in SAR images," in 2nd Int. Conf. Adv. Comput. Commun. Autom. (Fall), IEEE, pp. 1-5 (2016).

31. A. D. Nobre et al., "Height above the nearest drainage-a hydrologically relevant new terrain model," J. Hydrol. 404(1-2), 13-29 (2011).

32. C. Chow, A. Twele, and S. Martinis, "An assessment of the height above nearest drainage terrain descriptor for the thematic enhancement of automatic SAR-based flood monitoring services," Proc. SPIE 9998, 999808 (2016).

33. L. Xie et al., "Water-body types identification in urban areas from Radarsat-2 fully polarimetric SAR data," Int. J. Appl. Earth Obs. Geoinf. 50, 10-25 (2016).

34. H.-F. Ng, "Automatic thresholding for defect detection," Pattern Recognit. Lett. 27(14), 1644-1649 (2006).

35. N. B. Duy, "Automatic detection of surface water bodies from Sentinel-1 SAR images using Valley-Emphasis method," Vietnam J. Earth Sci. 37(4), 328-343 (2015).

36. S. Martinis, S. Plank, and K. Ćwik, "The use of Sentinel-1 time-series data to improve flood monitoring in arid areas," Remote Sens. 10(4), 583 (2018).

37. N. Otsu, "A threshold selection method from gray-level histograms," IEEE Trans. Syst. Man, Cybern. 9(1), 62-66 (1979).

38. J. Li and S. Wang, "An automatic method for mapping inland surface waterbodies with Radarsat-2 imagery," Int. J. Remote Sens. 36(5), 1367-1384 (2015).

39. A. Baraldi and F. Panniggiani, "An investigation of the textural characteristics associated with gray level cooccurrence matrix statistical parameters," IEEE Trans. Geosci. Remote Sens. 33(2), 293-304 (1995).

40. R. M. Haralick, K. Shanmugam, and I. H. Dinstein, "Textural features for image classification," IEEE Trans. Syst. Man Cybern. SMC-3(6), 610-621 (1973).

41. D. Amitrano et al., "A new framework for SAR multitemporal data RGB representation: rationale and products," IEEE Trans. Geosci. Remote Sens. 53(1), 117-133 (2014).

42. S. G. Dellepiane and E. Angiati, "A new method for cross-normalization and multitemporal visualization of SAR images for the detection of flooded areas," IEEE Trans. Geosci. Remote Sens. 50(7), 2765-2779 (2012).

43. M. H. Slovak, "Maximum-likelihood method for determination of membership in open clusters," Astron. J. 82, 818 (1977).

44. A. J. Grant et al., "Ecology and biology of nuisance algae in rice fields," A Report for the Rural Industries Research and Development Corporation, University of Sydney, NSW, p. 38 (2006).

45. A. Dehni and M. Lounis, "Remote sensing techniques for salt affected soil mapping: application to the Oran region of Algeria," Proc. Eng. 33, 188-198 (2012).

46. Z. Aly, F. J. Bonn, and R. Magagi, "Analysis of the backscattering coefficient of salt-affected soils using modeling and RADARSAT-1 SAR data," IEEE Trans. Geosci. Remote Sens. 45(2), 332-341 (2007).

47. S. Mathieu-Marni, S. Kuttikkad, and R. Chellappa, "Context-aided false alarm reduction for SAR automatic target recognition," in Proc. Int. Conf. Image Process., IEEE, p. 885-888 (1997).

48. F. Bi et al., "A hierarchical method for accurate water region detection in SAR images," in IET Int. Radar Conf. Proc. (2015).

49. F. Sun et al., "Comparison and improvement of methods for identifying waterbodies in remotely sensed imagery," Int. J. Remote Sens. 33(21), 6854-6875 (2012).

50. W. Huang et al., "Automated extraction of surface water extent from Sentinel-1 data," Remote Sens. 10(5), 797 (2018).

51. N. S. Morandeira et al., "Mapping plant functional types in floodplain wetlands: an analysis of C-band polarimetric SAR data from RADARSAT-2," Remote Sens. 8(3), 174 (2016).

52. I. Caballero and R. P. Stumpf, "Retrieval of nearshore bathymetry from Sentinel-2A and 2B satellites in South Florida coastal waters," Estuarine, Coast. Shelf Sci. 226, 106277 (2019).

53. EcoDevelopment S.A., "Water monitoring $\mathrm{S}$ in Central Macedonia," Project WaMoS, 20182021 https://ecodevsa.maps.arcgis.com/apps/MapSeries/index.html?appid=c860d92a87b3449bb df3797c11a8e5ed (access 4 February 2021). 
Georgios Ovakoglou is a geomatics and surveying engineer with a degree in geographical information management and applications (the Netherlands), conducting research toward the application of remote sensing and GIS in environmental sciences. His present activities concern the spatio-temporal analysis of satellite images for applications in agriculture (vegetative, hydrological and topographical parameters modeling) using remote sensing data at different scales, and his work has been published in several journal articles and conference papers.

Ines Cherif is a physics engineer, specialized in modeling natural resources, mapping evapotranspiration, and monitoring surface water and flooded areas with remote sensing and GIS. She has been involved in numerous EU and national projects and authored and co-authored several publications, focusing on modeling vegetation and soil water parameters with visible, thermal, and radar satellite images.

Thomas K. Alexandridis is an agronomist with a specialization in remote sensing and geoinformatics. His research interests include environmental, agricultural, and water resources monitoring and modeling using Earth observation, and spatial analysis of geographic data in GIS. He has authored and co-authored more than 100 journal and conference papers and has participated in more than 30 research projects, in several of them as principal investigator.

Xanthoula-Eirini Pantazi is an expert in bio-inspired computational systems and data mining. Her research interests include precision farming, plant stress detection, sensor fusion, machine learning, and non-destructive sensing of bio-material and crop protection. Her research interests also include bioinformatic applications in field phenotyping with autonomous platforms (e.g., UAV and robots). She has authored and co-authored on research monograph, more than 35 journal and conference papers, and has participated in more than 15 research projects.

Afroditi-Alexandra Tamouridou is an agronomist with a specialization in intelligent automation and smart sensing in biosystems engineering. Her research interests include precision farming, remote sensing, spectroscopy, artificial neural networks, machine learning, weed and disease monitoring, and robotics. She has authored and co-authored more than 20 journal and conference papers and has participated in more than 10 research projects.

Dimitrios Moshou is an electrical engineer with specialization in AI, machine learning and neuromorphic systems. His research interests include intelligent control, pattern recognition, data fusion, robotics and non-destructive quality control and monitoring of bio-products and crops. He has authored and co-authored more than 250 journal and conference papers and has participated in more than 50 research projects as principal investigator.

Xanthi Tseni is a geologist with specialization in environmental data management and methods of developing decision support systems for risk assessment. Her research interests include precision agriculture, image analysis and modeling. She has authored and co-authored nine journal papers and has participated in five research programs. Since the beginning of 2017, she has been in charge of the geoinformatics team of Ecodevelopment, with the main objective of analyzing geographical data and modeling.

Iason Raptis is a data analyst, currently studying applied informatics at the University of Macedonia (Thessaloniki, Greece). His research interests focus on machine learning, artificial intelligence, data analysis, and storytelling. He has been involved in projects of pre-processing and manipulating geographical and field data, mainly for mosquito control and precision agriculture.

Stella Kalaitzopoulou is a biologist and has worked at Ecodevelopment SA since 1997 (10 publications, 190 citations, Scopus). She is the director of the Mosquito Control Department of the company and responsible for the quality assurance. She has significant experience in managing large-scale mosquito control projects (operational planning, technological upgrades, staff training, and communication). She has managed the WNV epidemics and the recent malaria cases that occurred in Central Macedonia, Greece, both at operational and communication level. 
Spiros Mourelatos is a president and CEO of Ecodevelopment SA (46 publications, 697 citations, ResearchGate). He holds his PhD in hydrobiology and has significant experience in management and data analysis in environmental sciences. He is recognized as one of the leading experts in the field of wide-area mosquito control. He was president of the European Mosquito Control Association (EMCA) in 2015-2016 and is a certified expert of the World Health Organization (WHO). 